\title{
NEW ZEALAND RESEARCH
}

\section{A Midwife Who Knows Me:}
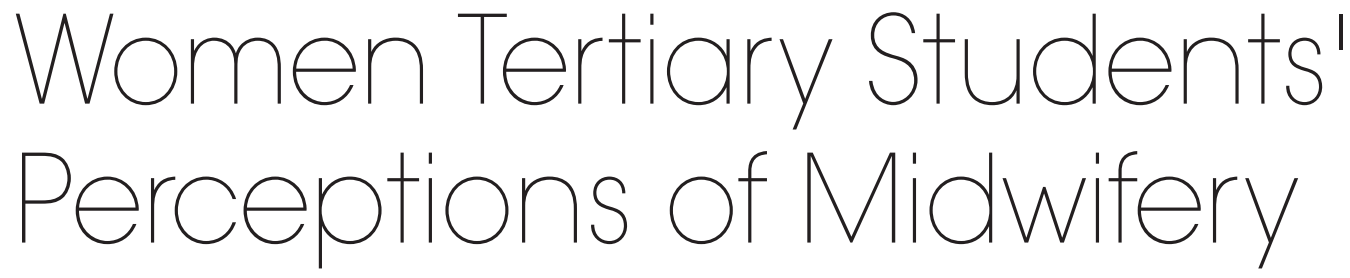

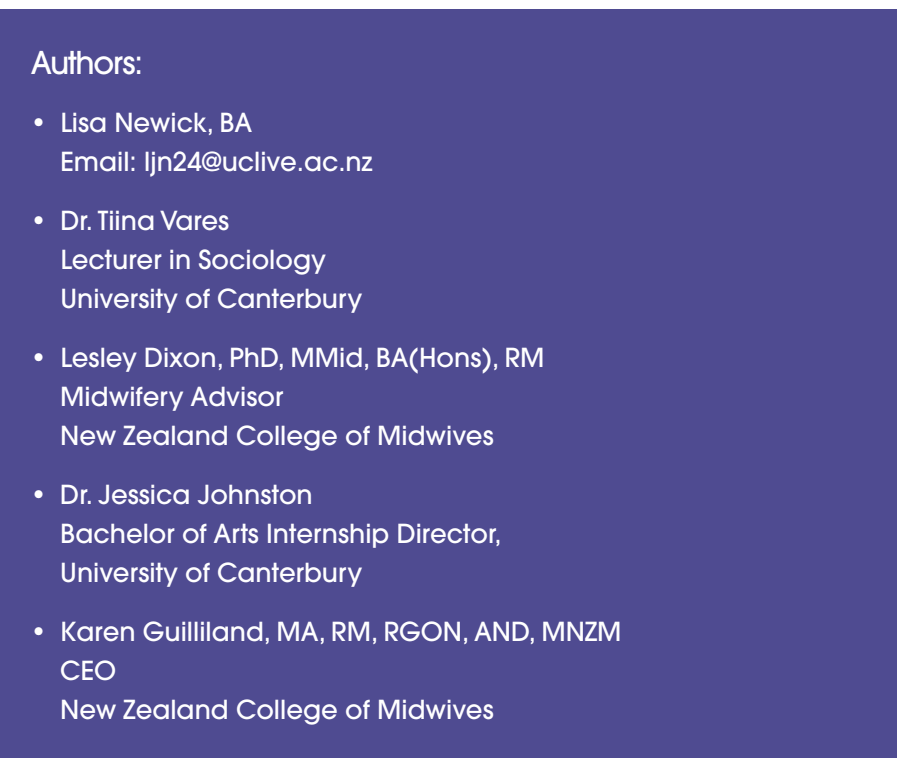

\section{ABSTRACT}

There is little information about how young women view midwives and the maternity services yet they are the future potential consumers of maternity services. How their expectations are formed is important. This study of young female university students has explored their understanding about midwives and maternity care. Two small focus groups involving eleven undergraduate women were held to discuss midwifery and maternity services. Qualitative thematic analysis was used to identify three overarching themes. Firstly, there was a perception of midwives as providing a highly personalised and professional service but that particular social qualities were also necessary. Secondly,the midwifery partnership model of practice was found to be embedded in the women's understanding of the maternity system. Lastly, storytelling from friends and relatives was found to be the main source of the construction of these young women's perceptions. Storytelling was considered a trustworthy source of information and privileged above media representations. Employing the power of personal storytelling is a strategy that may be useful when seeking to connect with young women who are future potential users of midwifery and maternity services. This strategy could support and improve knowledge and understanding of the New Zealand/ Aotearoa midwifery and maternity services.

\section{KEY WORDS}

midwifery, continuity of care, undergraduate students, storytelling, maternity care.

\section{INTRODUCTION}

Two decades ago, the introduction of the midwifery partnership model in New Zealand/Aotearoa was a world-leading initiative. Within this model, midwives work as autonomous health practitioners seeking to empower women as experts in the natural and normal process of pregnancy and birth through a power-sharing partnership (Guilliland \& Pairman, 2010). More recently, a media backlash has undermined midwives and their professional credibility (Chisholm, 2011; Exton, 2008; Guilliland \& Pairman, 2011; Haines, 2009). In response, as the professional organisation and recognised voice of midwives, the New Zealand College of Midwives has been considering optimal ways of publicly disseminating accurate information about midwifery and maternity services.

Maternity care in New Zealand is fully government funded for all resident, eligible women, who can choose a Lead Maternity Carer (LMC) to co-ordinate and provide maternity services. An LMC can be a general practitioner, an obstetrician, or a midwife (Ministry of Health, 2007a). The majority of New Zealand pregnant women (78\%) choose a midwife to provide their LMC services and gain continuity of care from the one health care professional, from early pregnancy to six weeks postpartum (Ministry of Health, 2007b). In many aspects, the New Zealand midwifery partnership model is woman-centred and differs from maternity service models found in other countries.

There is little research exploring the understanding and perspectives of young women about midwives and maternity services. One study was found involving American university students enrolled in a Maternal Child Health course, which analysed anonymised online discussions about midwifery (DeJoy, 2010). Despite having access to core readings on midwifery training and practice, these students associated midwives primarily with homebirth and unsafe practice.

An Australian study found that while pregnant participants clearly understood that midwives were qualified to provide full maternity care, many women still requested a doctor at birth (Leen Ooi Boon, 2004). An American study found that pregnant women's beliefs about childbirth influenced their choice of health professional. Women who saw birth as normal and natural tended to select a midwife. Those who perceived birth as in need of medical assistance chose an obstetrician (HowellWhite, 1997). In the United Kingdom, mothers enrolled in one study were interviewed at several points during pregnancy and following the birth, and reported that midwives were their preferred maternity health professionals (Fraser, 1999). Consumer surveys in New Zealand have demonstrated consistently high levels of satisfaction with the LMC model of maternity care (Health Services Consumer Research, 2008; Ministry of Health, 2012). The 2011 consumer survey identified the highest level of satisfaction $(89 \%)$ when the LMC was a midwife.

In both America and Australia, midwives are concerned that inaccurate public understandings have a negative impact upon the midwifery profession (Brodie, 2002; Foley, 2005). The need for public education to improve knowledge about midwifery care was identified. Kimberly 
Kline (2007) analysed midwife-attended birth representations airing on prime time American television. She found that midwives were portrayed as controlling, and an irrational choice of maternity health carer. In New Zealand there have been several media reports that depict maternity care as problematic, with midwifery as the cause (Chisholm, 2011; Exton, 2008; Haines, 2009). This is despite the overwhelming consumer satisfaction outcomes and comparable perinatal mortality to the United Kingdom (UK) which has a similarly high quality collection of perinatal mortality data (Perinatal and Maternal Mortality Review Committee, 2012).

The aim of this research project was to explore the perspectives of a small group of female university students about midwifery and maternity care in New Zealand. This research was undertaken by a third year Bachelor of Arts student at the University of Canterbury and mother of two, supported by the New Zealand College of Midwives. The research project had Human Ethics Committee approval under the University of Canterbury internship programme.

\section{METHOD}

Focus groups were chosen as the most useful method to generate in-depth talk among groups of young women around the topic of midwifery. At Canterbury University, young female students of social sciences were recruited through presentations before lectures, online invitations to take part, direct approach, and word of mouth. All participants were given an information sheet and consent forms to read and sign. Two focus groups were facilitated using a discussion guide, which supported open conversation (Box 1). The first focus group consisted of seven participants which included a mother with recent experience of maternity services. No one else in this group had attended a birth. The second focus group consisted of four participants, three of whom had attended a birth in a support role. To stimulate dialogue towards the end of the second focus group, the facilitator introduced a North \& South magazine cover, current at the time, which was representative of negative media portrayal of midwives (Chisholm, 2011).

\section{Discussion Guide}

- Maybe pregnancy and childbirth are not too important to you at the moment, but we all have ideas about pregnancy and childbirth and I am interested in what you know.

- Does anybody have a friend or relative who is pregnant or become a parent recently? Can you tell us about that?

- What have you seen or read about pregnancy?

- We are hearing about midwives... when you think about a midwife, what comes to mind?

- Can anyone describe the role of a midwife? What have you seen or read about midwives?

- What do you think the advantages of having a midwife are? And disadvantages, if any?

Transcripts were analysed thematically (Braun \& Clarke, 2006) for both understandings of midwifery, and how those meanings were co-constructed. To protect the participants' identities, pseudonyms were used in the text. A feminist social constructionist approach was used (Kitzinger, 1994; Wilkinson, 1998). Three major themes, with subthemes were identified (Table 1), all of which are linked to, and reinforced by, the others.

\section{FINDINGS \\ PERCEPTIONS OF MIDWIVES}

\section{Personalised service}

Participants articulated personalised care as an essential part of a midwife's professional services. There was an understanding that antenatal, intrapartum and postnatal care would be provided by the same midwife throughout. This long period of time would support the development of a deep familiarity - a client would know the midwife but also the midwife would know her. It was expected that this familiarity included knowledge of the woman's background, medical history, and emotional needs:

If I was thinking about having a child, I'd definitely want a midwife who understood what I wanted and my needs. I think it's quite important to have that belief that they're going to do what you want and support you in the way you need to be supported (Jane).

A midwife was perceived as being familiar with a client's personal beliefs, needs, and wants around pregnancy and birth, and as actively supporting these as well.The expectation of a supportive midwife also included active communication around education, informed decision-making and advocacy, to ensure the woman's specified needs and wants were met:

I think that women who are pregnant or give birth should be given all information that is possibly available, all options and then whatever they decide, that should be okay... I mean, as long as the client, the woman, is well-educated to make that decision, then that's the support she should get (Jade).

Midwives were expected to be unequivocally available for births. Some stories detailed birth experiences that were seen to be negatively compromised because the LMC midwife was not available and a backup midwife attended. The Section 88 contract of service specifications for LMC care requires that the LMC or a backup LMC is available 24 hours a day, seven days a week. LMC midwives have an arrangement with another LMC midwife to provide support and back up to their caseload during time off. This arrangement was constructed by participants as adversely affecting the birth experience:
My sister went into labour early, and the midwife wasn't available and so she had to talk to another one. That midwife said "Ohh, just have a bath, you'll be fine". My sister goes through so much pain all the time- she has quite a high threshold of pain tolerance and the other midwife knew this. At 11 o'clock at night they ended up taking my sister in, and they were "Oh my goodness you're seven centimetres dilated" and apparently that's when most women are screaming. And the other thing was my nephew was, do they call it breech, he was round the wrong way. So if it had been like another hour or whatever, well both my sister and he would have died. So, not having the right midwife caused all that havoc (Laura).

The lack of an existing familiar relationship was framed as contributing to increased danger. Jade, the only participant who had given birth, shared a story with similar concerns about a backup midwife:

When I couldn't have my proper midwife there and had to have a backup one instead, I was absolutely distraught. I hadn't had much to do with this other woman (Jade).

She didn't understand your background (Emily).

She didn't really know anything about me (Jade).

\section{Table 1}

\begin{tabular}{|l|l|l|}
\hline Perceptions of Midwives & Perceptions of the Maternity System & Construction of Perceptions \\
\hline - Personalised Service & $\bullet$ Midwives as the Lead Maternity Carers & $\begin{array}{c}\text { - Storytelling and Second-hand } \\
\text { Experience }\end{array}$ \\
\hline - Professional Expertise & - Birthplace Understandings & $\bullet$ Media Representations \\
\hline - Social Qualities & - Birth and Risk & \\
\hline
\end{tabular}


And you don't know her either. It's like some stranger in the room (Sophie).

Exactly (Jade).

It's a difficult time as well to have a stranger there (Lydia).

These discussions suggest that women want the midwife 'who knows me' available for labour and birth, to contribute to feelings of safety and support. Because the backup midwife did not 'know the woman', personalised midwifery care was seen to be disrupted. While participants did not always expect to control birth timing, they did expect to control who was at the birth. The unpredictable timing of births was discussed as part of the midwifery job description and that midwives had to find a way around that potential dilemma within a caseload, to be available for the birth. That the backup midwife was part of the solution to this issue was not well understood.

\section{Professional Expertise}

Experience and knowledge were discussed as being important qualities for a midwife. A high level of experience in terms of having attended many births was linked to expert knowledge. That midwives 'knew what they were doing' was understood as promoting a positive level of reassurance for the woman:

To have somebody who is knowledgeable and has experience in those kind of things, who can provide you with that and make you feel comfortable and assure you about the situation, is important (Emily).

Within personalised midwifery care and support a woman is empowered as the expert in knowing what is best for her. At the same time, the midwife is positioned as specialising in pregnancy and birth. Below, Jane describes attending a birth where both the midwives and the birthing mother saw themselves as the predominant expert:

She was pretty clear that she didn't want any assistance, she didn't want any drugs and she didn't want any gas even, and there came a point where they were trying to make her have gas and... she's pretty stubborn so she didn't but I could see how easily you could? And I found that quite interesting, that there was this perception of what was going to be best for her regardless of what she really felt, even though she was the one experiencing it (Jane).

\section{Social qualities}

Participants noted a range of social qualities that enhanced the professional proficiency and individualised service that midwives brought to the relationship. One participant preferred a no-nonsense approach while another desired a sensitive concern for emotional wellbeing. For most participants, it was important that midwives have empathy and the 'care factor':

I think it's someone who is able, especially if it's your first child - even though they've seen it a hundred times - to be able to have empathy with what you were going through for that first time (Jane).

Some participants shared narratives in which midwives were framed as insensitive and without a consistently empathic approach. In the situation below, the midwife made a negative remark which remained in the woman's memory long after midwifery care had been completed. The woman shared her experience with family and friends which contributed to an adverse view of that midwife:

My sister, when she was having her child, she was nineteen, she had really bad endometriosis and polycystic ovaries, and she was like "Well I'm going to have to get a hysterectomy". The midwife said "Oh, don't do that. What if something happens to your son, what if he gets run over and killed?" My sister has had a hysterectomy now, she didn't really have a choice. She's got one child, she can never have another one. And it's just stuck with her, what that midwife said. That midwife just was not thinking, especially how that would psychologically affect my sister (Liz).

\section{PERCEPTIONS OF MATERNITY SERVICES \\ Midwives as the Lead Maternity Carers}

Midwives were accepted as the predominant option for a Lead Maternity Carer (LMC) within the New Zealand maternity system. In all the birth stories shared, midwives were talked about:

Everyone I know has had a midwife...so I see it as being part of what
people use, when they have children in New Zealand (Jane).

No birth stories mentioned doctors. Doctors were only referred to as being potentially present at births, and no more than that:

You'd probably get more experience from a midwife, maybe, of the bigger picture of childbirth. Before and after. As opposed to a doctor who might be more surgically oriented, maybe. Just looking at the birth, then off you go (Fiona).

\section{Birthplace understandings}

Birth stories were shared about midwives facilitating births at home, in birthing units, and in hospitals. Many hospitals in New Zealand transfer women to primary units for postnatal care, or discharge them home within 48 hours of the birth. While midwives were positioned as advocating for mothers against hospital demands to leave, concerns were raised about hospital services moving new mothers out too quickly:

Lots of people talk about places like (Name) Hospital and getting booted out of there real fast. They just want to flick you out straight away, which is dodgy because then you hear about people having complications after they get home. And they don't know what to look for, what's right and what's wrong and you're putting them, the baby and mother, in a dangerous position and they seem to be all about turnover and not care (Emily).

This perception that women were discharged from hospital too early, contributed to fear and worry that new parents were under-supported by maternity services at a crucial time. There was not a clear understanding that some secondary/tertiary hospitals transfer new mothers and babies to primary units for postnatal recovery and support.

\section{Birth and Risk}

In this study, birth was linked to risk. While acknowledging risk, the narratives below also describe positive perceptions of birth. They identify birth as turning out 'all right' with midwifery expertise and medical technology on hand if needed. These views came from the second group of four participants, including three women who had the experience of being at a birth as support people:

But you know, actually, what can go that wrong really? Like if you've got the backups there as well, I think it would be good. Oh, I think I'd be alright (Anna).

I think, with like the precautionary principle where "you must go to the hospital just in case anything goes wrong," but for the most part things don't go seem to go wrong (Fiona).

Other participants shared a perception of birth as potentially dangerous. This was more prevalent in the first focus group where none of the women had attended a birth, except a mother, Jade:

You have to trust that midwife knows what they're doing and so you're putting a lot of trust in someone and [they] have to know what they are doing because if there are complications, it's life and death (Andrea).

These discussions reveal contradictory views around birth and risk. Birth was seen as dangerous and unpredictable, alongside a perspective of birth as a positive experience, despite risk.

\section{CONSTRUCTING PERCEPTIONS}

\section{Storytelling and second hand experience}

Perceptions about pregnancy, birth, midwives and maternity care were constructed through the sharing of stories. The stories related to direct birth experience and second-hand experience. No one referred to any formal information such as books, leaflets or websites. In these dynamic 
discussions, participants enacted the social interaction that was the primary source of information about midwifery care within this context word of mouth:

I was on the phone all the time trying to find someone to be my midwife. And now all of my friends, who have heard my experience, anytime they are pregnant, that's it, they are on the phone (Jade).

That word of mouth was the main source of information about midwives was consistently reinforced. Jade's first-hand account of childbirth influenced the discussion within that focus group. The other participants privileged her experiences as expert. As a result, they articulated examples of turning points, where some young women seemed to change their minds and construct new meanings in response to the perceived credibility of storytelling:

From both my experiences of being in the hospital, it's not the midwives, it's the hospital staff who are really eager to get the women out of the door (Jade).

It's horrible, if people get kicked out early? What will they do? (Andrea). I'm pretty sure if I had had a baby for four hours, and I was worn out, I'd be thinking "what the hell have I got myself in for?" (Ellie). It already puts me off having children (Emily).

The sharing of second-hand stories by participants also indicated that new mothers have a desire to tell their stories of pregnancy, birth, midwifery care, breastfeeding and new motherhood, including the good and the bad of it:

I've got a couple of friends who have just had babies recently and they have both talked about this whole, kind of, innocent, pure, naive vision that most people have. And then the nitty-gritty of it, and they appreciated having someone to talk to about the nitty-gritty, the crappy parts about being pregnant and the hard stuff about giving birth (Jane).

\section{Media Representations}

Participants talked about media representations of pregnancy and birth in fictional movies and television shows, celebrity accounts from popular women's magazines, or from the internet. This talk was prompted by the facilitator with the question "what have you seen or read about pregnancy and birth?" There was talk of how these life events are often depicted as wonderful and hassle-free. However, participants were quick to dismiss these representations as inaccurate in the context of real life pregnancy and birth:

You always see celebrities say that pregnancy is the best time of their lives (Andrea).

Then you hear people and they say, "That was the most horrible six hours of my life" (Ellie).

Six hours? But what about 36 hours? (Sophie).

To stimulate talk in one of the focus groups the then current issue of a national magazine with a cover story criticising midwifery care was introduced late in the discussion. The group read the cover as being deliberately shocking. Participants were critical of the headline of "the myth of natural childbirth" and stated they considered that birth was a normal and natural event:

Obviously it's a natural event and I think that's the thing with midwives in New Zealand, in that it doesn't have to be all about doctors. It can be about midwives (Anna).

\section{DISCUSSION}

While these findings cannot be generalised, the perceptions of midwifery identified in this small group suggest that the midwifery partnership model is embedded in the New Zealand maternity system. Participants were very aware of women-centred care from midwives. Many understood that the client/midwife relationship was based on shared power and familiarity. This included an expectation of a supportive midwife, prepared to respect both the philosophical beliefs and clinical preferences of the client.

Continuity of caregiver was also well understood. This included the framing of 'my midwife' as consistently available. It was not enough for a woman to know her midwife - the emphasis was placed on a midwife 'who knows me', particularly at the birth. The same understanding did not extend to the role of the backup midwife. This was based on a concern that the backup midwife would not have sufficient knowledge about the woman to provide safe and appropriate care. It can be suggested that uninterrupted continuity of care from the same LMC was viewed not just as essential but as a right. From this small amount of nongeneralisable data there may be a lesson for some midwives, to review their practice and consider how they can ensure that the backup midwife has a more visible and meaningful contact with women prior to birth to establish a relationship, in the event that the LMC is not available.

This discussion indicates the very high, and some may argue, unachievable and unsustainable expectations participants placed on midwives. Midwives are perceived to provide highly individualised care, based on expert knowledge and experience, all delivered in an unfailingly available, accommodating, friendly and sensitive manner. This demand for non-negotiable, individualised care may be attributable to the characteristics of Generation Y, an age-related term which applied to these research participants. It could be argued that Generation $\mathrm{Y}$ is assertive, with a sense of entitlement and accustomed to highly personalised consumerism (Twenge, 2007).

The differences between midwifery care and that of doctors were understood. The perception of midwives as experienced in practice and clinically knowledgeable meant that midwives were seen as professionally accountable as well. One implication of midwives being seen as both autonomous and liable, is that they are held as fully and individually responsible for births, particularly those that lack an optimal outcome.

Birth and risk were linked. There were competing and contradictory understandings of birth as dangerous, and of birth as a normal and natural event. This suggests that midwives in New Zealand who practise within the midwifery partnership model may care for women who view birth within contradictory framings. What was noticeable was that while pregnancy and birth were acknowledged as potentially physiologically risky, this was also an emotionally important and special time in a woman's life, demanding specialised and supportive midwifery care. There was less clarity around the maternity system, with some confusion over the provision of immediate after-birth care for mothers and babies. This uncertainty may be explained using Maria Zadoroznyi's argument (cited in Leen Ooi Boon, 2004) that the workings of the maternity system become visible only when a woman directly experiences midwifery care, including knowledge of the role of the backup midwife.

Other than direct experience of birth, knowledge about midwifery was generated through social interaction. Participants privileged stories of direct experience and second-hand accounts of pregnancy and birth. Kline (2007, p. 20) reinforces the social nature of such information in her statement that "the experiences of pregnancy and childbirth engender expectations, desires and concerns; thus women seek advice and guidance from others with experiences and knowledge." Word of mouth was seen as a credible source of knowledge about midwives, while no formal information sources were named. However, negative perceptions of maternity care based on individual experiences seemed to be extended to apply to midwifery and maternity services in general. This supports the idea that public perceptions of midwives and midwifery are engendered rather than understood (Guilliland \& Pairman, 2011).

Word of mouth and experience of birth were more influential than media depictions in forming perceptions of midwifery. This can be seen as a positive sign for the midwifery profession. Critical media representations may not negatively influence perceptions of midwives that young women have, for two reasons. Firstly, in this study many participants were able to thoughtfully challenge media depictions, maybe because they were undergraduate students. Secondly, such reports are not necessarily of current interest to this age group (Zadoroznyi cited in Leen Ooi Boon, 2004). This was true in respect to the magazine cover introduced in the second focus group. All the women disregarded it as sensationalist, and were previously unaware of that particular cover, article and debate. 
Participants in this study had many second-hand stories to share about pregnancy and birth, which suggests that mothers do talk about birth experiences. In New Zealand, midwives provide consumer feedback forms to their clients so that both positive and negative feedback can be provided. This feedback mechanism helps midwives to reflect on their care and supports sensitivity and improved understanding of the woman's perspective. Some women however, may retain negative criticism for word of mouth settings which do not include the midwife or midwifery profession such as conversations, online blogs, or other social media.

\section{Recommendations to support improved understanding}

As an appropriate medium through which to engage with the current generation of potential clients and new mothers, the internet may provide an opportunity to spread relevant information about midwifery care. Harnessing the power of storytelling is a useful tool in rectifying knowledge deficits and reinforcing positive perceptions of midwives. Storytelling has a long tradition in education. Carol Haigh and Pip Hardy (2010, p. 410) explain that "storytelling has been used both to engage service users and to transmit health messages". A suggestion for public education around midwifery and maternity services is the use of relevant, real-life stories in short multi-media clips. These 'digital stories' have been found to be powerful in raising awareness in health disciplines (Kirk, Tonkin \& Burke, 2007; Haigh \& Hardy, 2010). Involving people of influence is critical for success in delivering the 'message' (Kirk et.al., 2007). In this context, real-life personal narratives from new young mothers with positive experience of LMC care could be useful.

\section{Limitations}

This research has been a small qualitative explorative study and cannot be generalised to all young tertiary students. As with all research of this nature, the meanings interpreted could be read differently by other researchers.

\section{CONCLUSION}

One of the authors, Guilliland, has argued that "midwives in New Zealand have come to acknowledge the pivotal role the consumer plays in the protection of their profession" (1989, cited in Guilliland \& Pairman, 2010 , p. 16). By engaging with future potential consumers, we have explored how a small group of tertiary students view midwifery and maternity services.

Findings show that the participants had high expectations of a midwife 'who knows me', including individualised care, empathic understanding and support, and active communication. LMC midwives were unrealistically expected to be always available for labour and birth. Backup midwives were considered negatively and as potentially contributing to safety concerns owing to a lack of shared familiarity, and in-depth knowledge of the woman's history and pregnancy.

Midwives were acknowledged as both professionally knowledgeable and accountable. Participants clearly understood the partnership model of midwifery practice as embedded within the New Zealand maternity system. This included shared power and continuity of care. Midwives were positioned as the main option for LMC care within the New Zealand maternity system. However there was some confusion about maternity services themselves, and in particular, a perceived lack of postbirth hospital support.

Great importance was placed by participants on the experiences of their friends, family and others to co-construct perceptions of maternity care and midwifery. They identified these storytelling accounts as influencing their choice of birthing support. No formal sources of information about midwives or maternity care were named. Significantly, participants demonstrated the ability to thoughtfully challenge critical media representations of birth and midwives.

Employing the power of personal story telling within digital social media is a possible platform with which to currently connect with young women. This suggestion combines well with the existing education efforts of the New Zealand College of Midwives. Together they can contribute towards a public education initiative of improving knowledge of midwifery among young women, the potential future clients of midwives. As a result, the midwifery profession may be further strengthened and validated here in New Zealand.

\section{ACKNOWLEDGEMENTS}

This project was undertaken as part of an undergraduate degree with the University of Canterbury and with support from the New Zealand College of Midwives. We would like to thank the participants for sharing their time and their stories.

\section{REFERENCES}

Braun, V. \& Clarke, V. (2006). Using thematic analysis in psychology. Qualitative Research in Psychology, 3, 77-101.

Brodie, P. (2002). Addressing the Barriers to Midwifery - Australian Midwives Speak Out. Australian College of Midwives Incorporated, 15, 5-14.

Chisholm, D. (2011). A Failure to Deliver. North \& South. August 2011, 39-51.

DeJoy, S. B. (2010). "Midwives are Nice, But...": Perceptions of Midwifery and Childbirth in an Undergraduate Class. Journal of Midwifery and Women's Health, 55, 117-123.

Exton, L. (2008). The baby business: what has happened to maternity care in New Zealand? Nelson: Craig Potton.

Foley, L. (2005). Midwives, Marginality and Public Identity Work. Symbolic Interaction, 28, 183-203.

Fraser, D. (1999). Women's Perceptions of Midwifery Care: A Longitudinal Study to Shape Curriculum Development. Birth. 26, 99-107.

Guilliland, K. \& Pairman, S. (2010). The Midwifery Partnership-A model for practice. Second Ed. Christchurch: The New Zealand College of Midwives.

Guilliland, K. \& Pairman, S. (2011). Women's Business: the story of The New ZealandCollege of Midwives 1986-2010. Christchurch: New Zealand College of Midwives.

Haigh, C. \& Hardy, P. (2010). Tell me a story - a conceptual exploration of storytelling in healthcare education. Nurse Education Today. 31, (4), 408-411.

Haines, L. (2009). Another unfortunate experiment? Listener. Issue 3586, 31 January 2009.

Health Services Consumer Research (2008). Maternity Services Consumer Satisfaction Survey Report. Auckland Health Services Consumer Research.

Howell-White, S. (1997). Choosing a Birth Attendant: the Influence of a Woman's Childbirth Definition. Social Science and Medicine, 45, 925-36.

Kirk, M., Tonkin, E. \& Burke, S. (2007). Engaging Nurses in Genetics: The Strategic Approach of the NHS National Genetics Education and Development Centre. Journal of Genetic Counselling. 17, 180-188.

Kitzinger, J. (1994). The methodology of Focus Groups: the importance of interaction between research participants. Sociology of Health and Illness, $16,(1), 103-121$

Kline, K. (2007). Midwife attended births in prime-time television: Craziness, controlling bitches and ultimate capitulation. Women and Language, 30, (1), 20-29.

Leen Ooi Boon, C. (2004). Primigravidas' perception of the role of a midwife. Australian Midwifery: Journal of the Australian College of Midwives. 17, 26-31.

Ministry of Health (2007a) Maternity Services: Notice Pursuant to Section 88 of the New Zealand Public Health and Disability Act 2000. Wellington: Ministry of Health.

Ministry of Health (2007b). Report on Maternity: Maternal and Newborn Information 2004. Wellington: the New Zealand Health Service.

Ministry of Health (2012). Maternity Consumer Survey 2011. Wellington: Ministry of Health.

Perinatal and Maternal Mortality Review Committee (2012). Sixth Annual Report of the Perinatal and Maternal Mortality Review Committee: Reporting mortality 2010. Wellington: Health Quality \& Safety Commission.

Twenge, J. (2007). Generation Me: Why today's young Americans are more confident, assertive, entitled - and more miserable than ever before. New York: Free Press.

Wilkinson, S. (1998). Focus groups in feminist research: power, interaction and the co-construction of meaning. Women's Studies International Forum, 21, (1), 111-125.

\section{Accepted for publication June 2012}

Newick, L., Vares, T., Dixon, L., Johnston, J., Guilliland, K. (2013). A Midwife Who Knows Me: Women Tertiary Students' Perceptions of Midwifery. New Zealand College of Midwives Journal, 47, 5-9. DOI: http://dx.doi.org/10.12784/nzcominl47.2013.1.5-9 